\title{
THE DESIGN AND ANALYSIS OF ELECTRIC VEHICLE GEARBOX CASING
}

\section{HARSHA. G ${ }^{1}$, SUNIL KUMAR ${ }^{2} \&$ MOHAN. ${ }^{3}$}

${ }^{I}$ Student, Department of Mechanical Engineering, Nitte Meenakshi Institute of Technology, Bangalore, India

${ }^{2}$ Professor, Department of Mechanical Engineering, Nitte Meenakshi Institute of Technology, Bangalore, India

${ }^{3}$ DGM (On highway R\&D) AVTEC Ltd, Hosur, Tamil Nadu, India

\begin{abstract}
This study includes Design analysis on the use of the Finite Elements Analysis method for two speed electric busses gear boxes. When designing the gearbox, the strength of the transmission system is very important. Using NX software, the 3D model is developed, and FEM is resolved with Ansys 14.5. Using statisticalanalysis, it is detected the total stress amount and displacement of the gearbox case. Dynamic analysis is used to find out the natural frequency of the gearbox casing. This process helps to determine how the gearbox case is optimized, in which it performs best without failure and has minimum loads on the case.In designing a gearbox housing, FEA should also be carried out to determine whether or not the design is safe.

KEYWORDS: Analysis of Gearbox, Electric Vehicles, Modal Analysis \& EV Transmission
\end{abstract}

Received: Jan 17, 2018; Accepted: Feb 07, 2018; Published: Apr 15, 2019; Paper Id.: IJMPERDJUN201919

\section{INTRODUCTION}

One of the most important system to consider in the design of a vehicle is the transmission system. In addition to the concept model developer, the noise and vibration control of the gearbox should also be concentrated. The noise is caused by meshing equipment through rooms and shafts into the gearbox. When the natural frequency and the frequency of excitation are equal, a gearbox failure will occur. The results of the analysis indicate the transmission vibrations in different modes. The frequency increases with the modes. Modal analysis results provide an overview of building dynamic behaviour. The calculation of the natural frequency in free running condition is done without the application of any restrictions on the case. The frequency with which every object vibrates if disturbed and allows itself to vibrate without an exterior force called "Natural Frequency." The natural frequency of any component is an inherent property of characteristics and no external force is used during the analysis. Natural frequency calculation damping is neglected. Without applying the restrictions and constraints, the natural frequencies of the transmission are calculated with free run in Ansys. Modal analysis had been carried out free of charge to determine the model's natural frequencies.

\section{MODELLING}

NX Unigraphics is a computer helped design software with multiple platforms. It will support various product development phases from concept development, design, analysis and production. The following are the major facilities provided by UG NX. A series of solutions for the development, modification and validation of complex forms in surface engineering. It is capable of creating three-dimensional components from metal sheets or any composite and moulded material, tooling components and mechanical assembly. It has a system for the design 
and distribution of electrical systems, such as fluid systems, heating, ventilation and etc. systems. Solutions for complex design and design modelling.

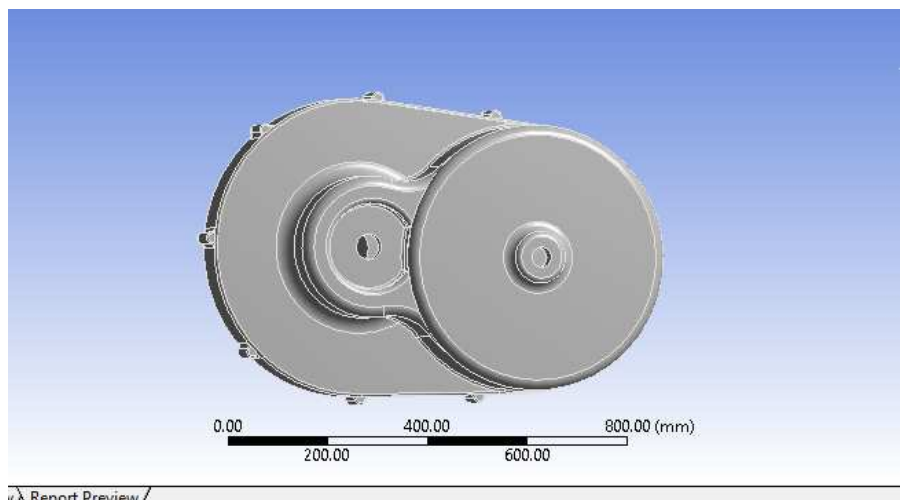

Figure 1: Modelling of the Electric Vehicle Gearbox

\section{MESHING}

It's a basic activity that helps transform the geometry built into nodes and elements. It consists of the geometric domain being discreted into valid analysis zones. Meshing therefore generates a discretized domain which serves as the base for the assignment and calculations of different quantities of analysis. The geometric definition in the space of problem essentially becomes a representation of a numerical solution in the solution space.

Type of meshing: Tetrahedral element mesh

Quality of mesh: Refinement fine mesh

Number of elements: 421554

Number of nodes: 683041

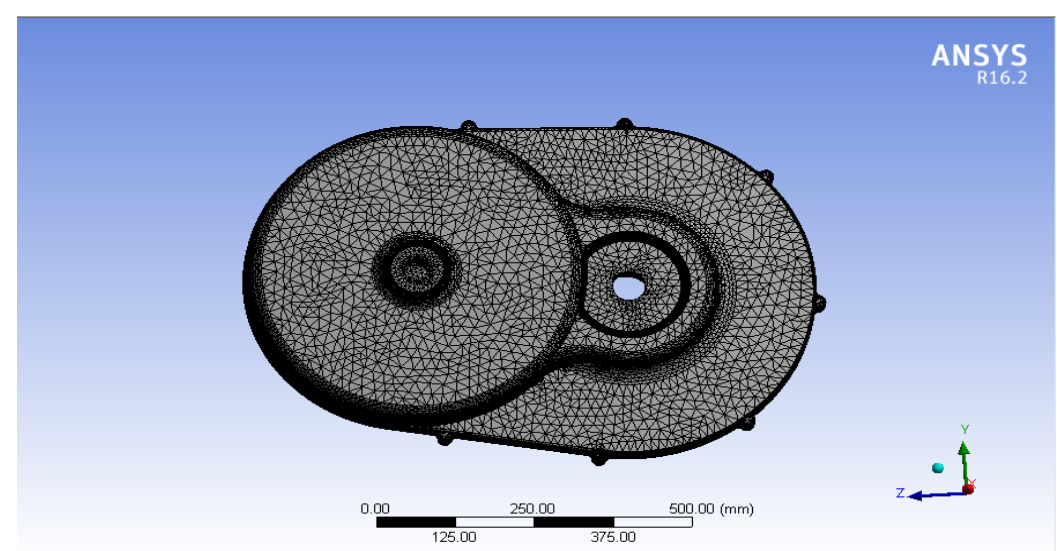

Figure 2: Meshing of Concept Model

\section{MATERIAL PROPERTIES AND BOUNDARY CONDITION}

As a gearbox material the aluminium alloy has been selected. In comparison with other material, it has better properties. And the weight is very low. And other properties, such as density, the young module and Poisson ratio, are necessary for the analysis. 
Table 1: Material Property of Gearbox Casing

\begin{tabular}{|c|l|c|c|}
\hline Sl No & \multicolumn{1}{|c|}{ Property } & Value & Unit \\
\hline 1 & Poisson ratio & 0.33 & - \\
\hline 2 & Youngs modulus & 71000 & $\mathrm{MPa}$ \\
\hline 3 & Density & 2770 & $\mathrm{Kgm}^{-3}$ \\
\hline
\end{tabular}

Boundary conditions can be applied to concept model geometry. There is different type of bearing loads applicable on gearbox casing

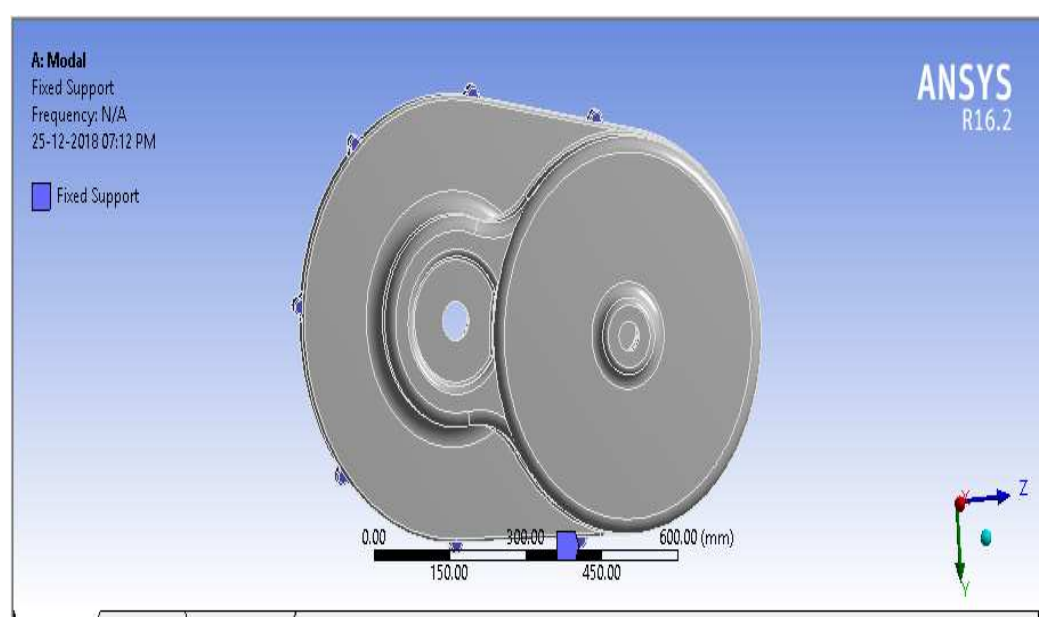

Figure 3: Fixed Support to Concept Model of Transmission Casing

\section{RESULTS AND DISCUSSIONS}

All analysis of the machine's components must be designed so that material limits cannot be exceeded by stresses and stresses that occur during operations. The material boundaries are determined by material properties and certain known theories of deformation. It must be analysed if the component is safe or fails to compare the maximum stress with yield or final stress. It undergoes two types of analysis:

- Modal analysis

- $\quad$ Static analysis

Modal Analysis Results: Calculations of the natural frequency of the case are made without any restrictions. Frequencies with which any object vibrates if disturbed and can vibrate alone, and this is known as "Natural Frequency" without any external forces. Natural frequency is inherent in any component or assembly and does not use external force during the analytical process. Natural frequency calculation damping will be neglected. By free running Ansys, the natural frequencies of the gearbox are measured without the use of any restrictions. The first ten natural frequencies of the model were found by modal analysis in free condition.

Table 2: Mode Shape and Frequencies

\begin{tabular}{|c|c|}
\hline Mode & Natural Frequency $(\mathbf{H z})$ \\
\hline 1 & 162.61 \\
\hline 2 & 286.58 \\
\hline 3 & 299.05 \\
\hline 4 & 381.54 \\
\hline 5 & 401.97 \\
\hline 6 & 521 \\
\hline
\end{tabular}




\begin{tabular}{|c|c|}
\hline \multicolumn{2}{|c|}{ Table 2: Contd., } \\
\hline 7 & 607.01 \\
\hline 8 & 667.5 \\
\hline 9 & 676.13 \\
\hline 10 & 704.71 \\
\hline
\end{tabular}

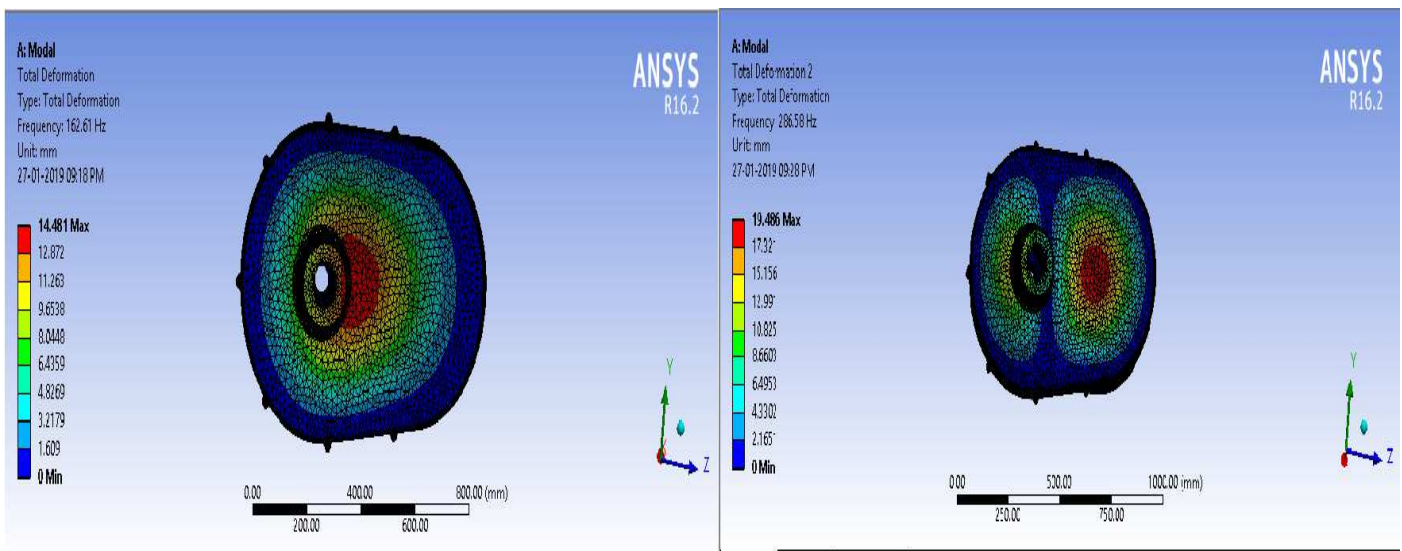

Figure 4(a): $1^{\text {st }}$ Mode of Electric Vehicle Transmission Casing
Figure 4(b): $2^{\text {nd }}$ Mode of Electric Vehicle Transmission Casing

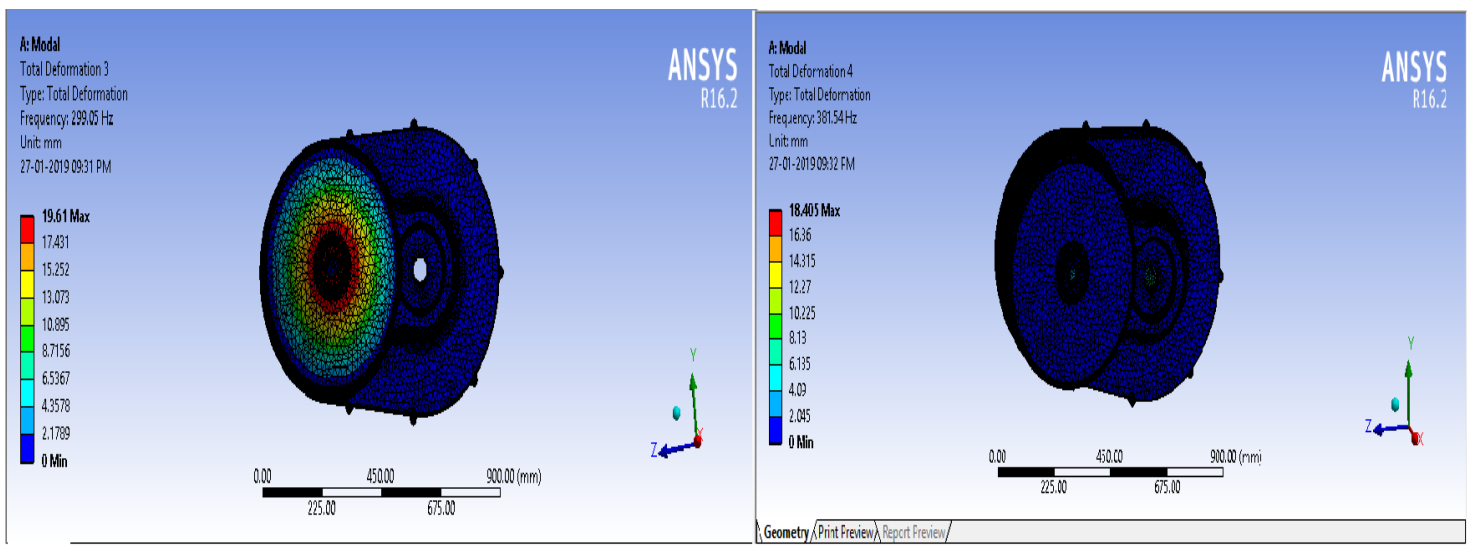

Figure 4(c): $3^{\text {rd }}$ Mode of Electric Vehicle Transmission Casing

Figure 4(d): $4^{\text {th }}$ Mode of Electric Vehicle Transmission Casing

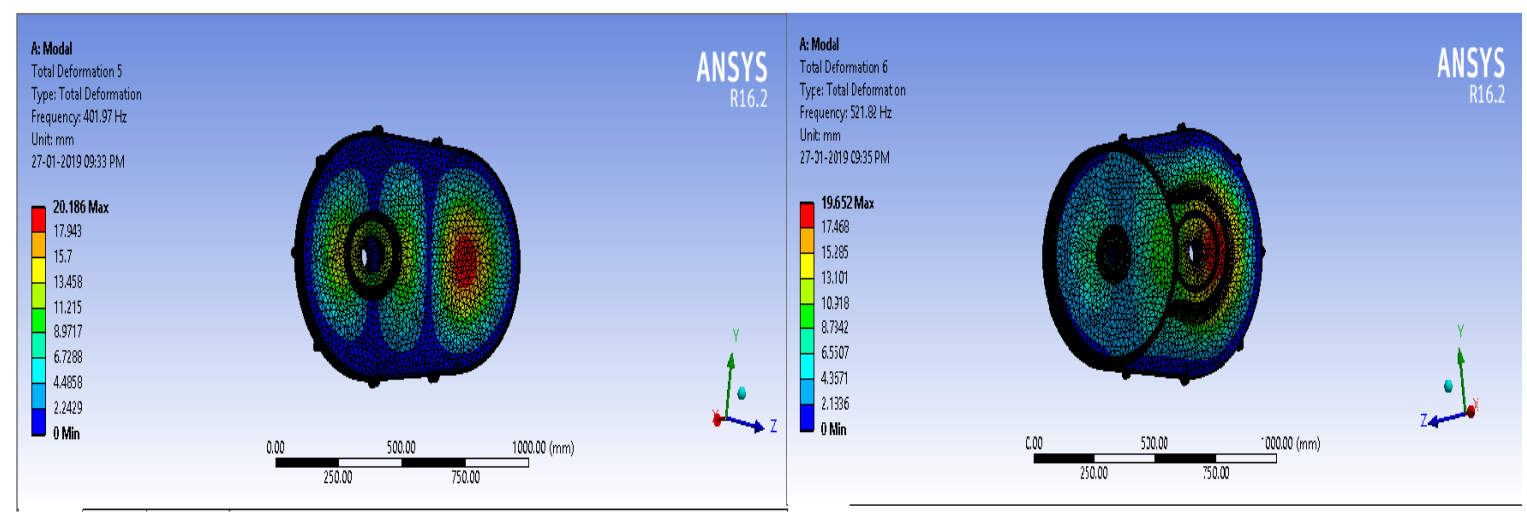

Figure 4(e): $5^{\text {th }}$ Mode of Electric Vehicle Transmission Casing
Figure 4(f): $6^{\text {th }}$ Mode of Electric Vehicle Transmission Casing 
Static Analysis Results: Linear static analysis means the calculated response - displacement or stress is associated linearly with force while not varying without time or insignificant time variation. The force applied is also used severally or in combination with each other. Often the load is applied to several loading sub - cases, in which any sub - case is a loading requirement. Linear static is a structural type that is used to address both linear and non - linear problems. The technique of the block Lanczons is used to solve the fundamental equation. Resonance conditions with gear mesh frequency i.e. operating frequency are evaluated. Gear mesh frequency $=\left(\mathrm{N}^{*} \mathrm{k}\right) / 60 \mathrm{~Hz}$ where $\mathrm{N}$ is the number of teeth on gear and $\mathrm{k}$ is the speed of the shaft.

\section{VON-MISES STRESSANALYSIS}

The figure shows the Von-misses stress for EV gearbox casing having a maximum stress value of $650.8 \mathrm{MPa}$ and minimum value of $0.0008 \mathrm{MPa}$.

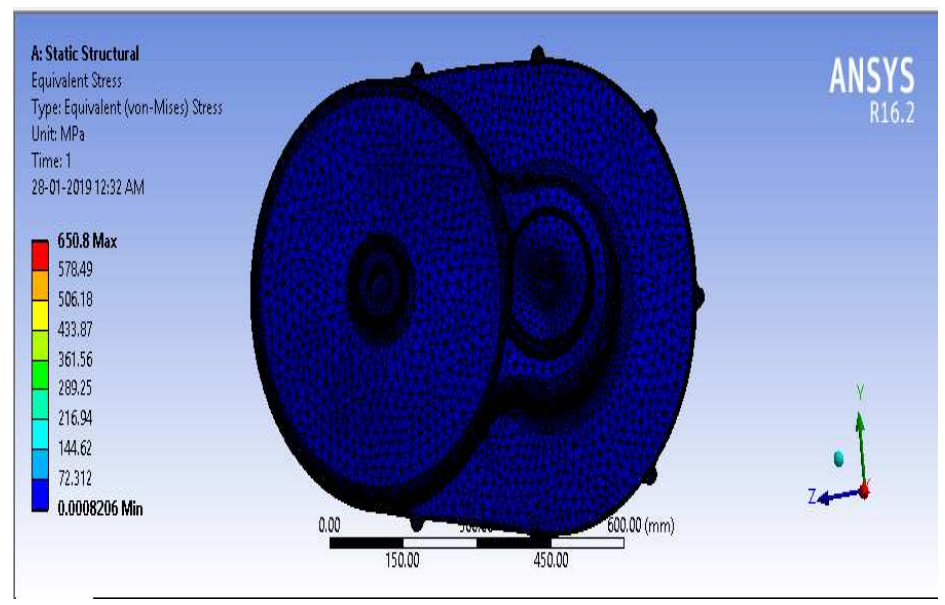

Figure 5: Equivalent Stress of Gearbox

\section{Deformation}

The figure below shows the maximum deformation of concept gearbox having maximum value of $0.4646 \mathrm{~mm}$

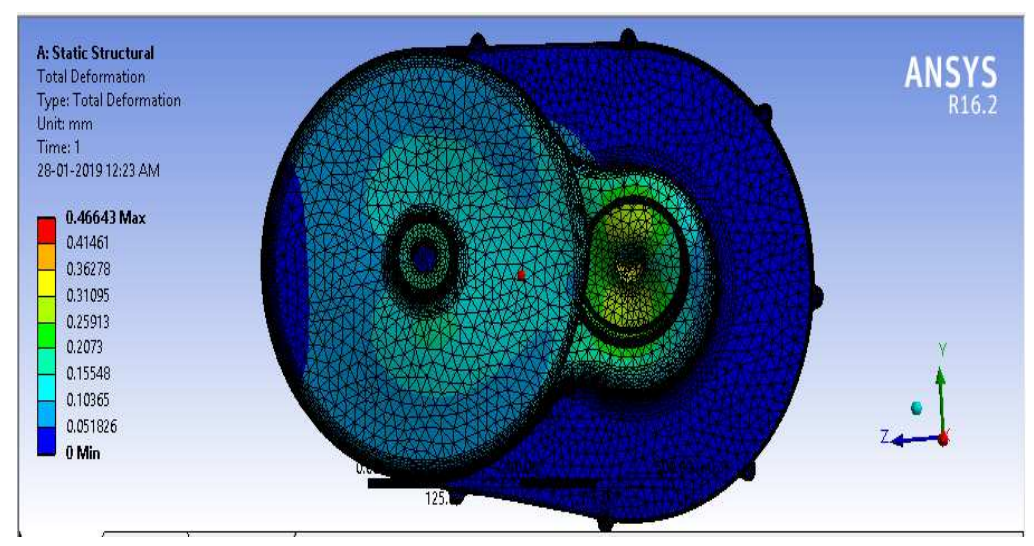

Figure 6: Total Deformation of Gearbox

\section{DISCUSSIONS}

- The results depict that the value of maximum value of von misses is $650.8 \mathrm{MPa}$ and minimum value of von misses stress is $0.00082 \mathrm{MPa}$. 
- In the frame it is found that the maximum deformation in the plate is $0.4646 \mathrm{~mm}$.

- The maximum stress and deformation are occurring near inner side extrusion of the gearbox casing and this can be minimized by providing more fillet radius.

\section{CONCLUSIONS}

The new gearbox casing has been developed and modelling is done from the Nx software along with the design calculations. By comparing both analytical and theoretical calculation our design will satisfy in all aspects. Using static analysis, we are able to conclude that the general amount of stresses and displacement is in permissible limit, so the structure is safe. The static analysis has helped in developing an optimum design ofthe gearbox casing. By considering the free-free condition, the natural frequencies of the gearboxcasing are compared with operating frequency. There is no condition of resonance found, so the structure is safe.

\section{ACKNOWLEDGMENT}

The author would like to thank Prof. Sunil Kumar (Guide, Associate Professor), NMIT, Bangalore, andMr.Mohan (DGM) AVTEC Ltd, Hosur, India.

\section{REFERENCES}

1. Lechner, G. and Naunheimer, H. Automotive Transmissions, Springer-Verlag Berlin Heidelberg 1999

2. Ashwani Kumar, Himanshu joshi, Pravin P Patil: Vibration based Failure analysis of heavy vehicle Truck transmission gearbox casing FEA. Composite materials, Proc. Of intl. conf. on mechanical Engineering, pp 251-259, INSB: 9789-351072713 (2014).

3. Selection of Electric Motor Drives for Electric Vehicles by X. D. Xue, K.W.E.Cheng, and N.C. Cheung

4. Design and control of two speed transmission for electric vehicles by fang, jiang sang.

5. Selection of electric motor drives for electric vehicle by X.D Xue.

6. Paul Walker, Nong Zhang. Modelling and control of novel two speed transmission for electric vehicles.

7. MehrdadEhsani, YiminGao, Gay Sebastien E, Ali Emadi. Modern electric, hybrid electric, and Fuel cells vehicles: fundamentals, theory and design. CRC Press: 2004

8. Alkahtany, L. A. Space Design for Hyperactivity and Distracted Attention (Methodology of Sustainable Materials Use).

9. Sirohi, S., Yadav, S., Ashok, B., Babu, V. et al., "Structural Analysis of Electric Vehicle Transmission Mount and casing for Different Materials, "SAE Technical Paper 2017-28-1961,2017,doi:104271/2017,doi:10.4271/2017-28-196 